\title{
THE EFFECT OF CCP-ACP ON THE SURFACE MICROHARDNESS OF PRIMARY TOOTH ENAMEL ERODED BY ANTIHISTAMINE SYRUP (IN VITRO STUDY)
}

\author{
Amira M Gaber ${ }^{1} B D S$, Karin M Dowidar ${ }^{2} M S c, P h D$, Dalia M Talaat ${ }^{3} M S c, P h D$
}

\begin{abstract}
INTRODUCTION: several cases of tooth erosion have been attributed to oral administration of liquid oral medications. Casein phosphopeptide-amorphous calcium phosphate (CPP-ACP) has gained much concern in modern dentistry for having anti- erosive properties. OBJECTIVES: The aim of the study was to evaluate the effect of CCP-ACP on the surface microhardness of primary tooth enamel eroded by antihistamine syrup.

MATERIALS AND METHODS: Twenty exfoliated primary teeth were collected and stored in normal saline till the beginning of the study. Then, each tooth was sectioned in a buccolingual direction into two halves, one served as study and other served as control. Specimens of both groups were immersed in antihistamine syrup for 30 min twice daily for 12 days to produce erosive enamel lesions. Study group specimens were treated with the remineralizing agent CPP-ACP once daily $3 \mathrm{~min}$ for 10 consecutive days and the control group specimens remained untreated. The samples were stored in artificial saliva between the erosive and the remineralizing cycles. the samples were evaluated for their surface microhardness by using Vickers microhardness testing. Data were collected, tabulated and statistically analyzed by using paired $t$ test. Significance level was set at $5 \%$. Bar charts were used for graphical presentation.

RESULTS: The mean surface microhardness of the sample was significantly decreased after erosion with antihistamine syrup $(\mathrm{P}<0.000)$. The mean surface microhardness of remineralized samples was significantly higher than that of the untreated samples $(P=0.01)$.

CONCLUSION: Treatment of eroded primary tooth enamel with CPP-ACP paste improved the surface microhardness invitro. Hardness testing is an accurate and reliable method to evaluate the enamel surface for demineralization and remineralization studies in vitro.

KEY WORDS: Dental erosion, CCP-ACP, Vickers microhardness.
\end{abstract}

${ }^{T}$ Bachelor of Dentistry, Faculty of Dentistry, Alexandria University, Alexandria, Egypt.

${ }^{2}$ Professor of Pediatric Dentistry, Faculty of Dentistry, Alexandria University, Alexandria, Egypt.

${ }^{3}$ Associate Professor of Pediatric Dentistry, Faculty of Dentistry, Alexandria University, Alexandria, Egypt.

\section{INTRODUCTION}

Dental erosion is recognized as an important cause of tooth structure loss, not only in adults, but also in children and adolescents. Therefore, it currently stands as a great challenge for the clinician, regarding the diagnosis, identification of the etiological factors, prevention and execution of an adequate treatment. Dental erosion, it is defined as the irreversible loss of dental hard tissue due to a chemical process of acid dissolution that does not involve bacterial plaque acid, and is not directly associated with mechanical or traumatic factors (1).

In the oral environment, tooth structure undergoes continuous demineralization and remineralization: if this balance is interrupted, demineralization will lead to a progressive deterioration of tooth structure (2).

Dental erosion is caused by exposure to acidic substances from a variety of sources, either of an intrinsic or an extrinsic source (3). The backflow of the gastric contents through the esophageal tract, in cases of Gastroesophageal reflux disease (GERD), rumination and bulimia, is considered as the intrinsic source of acids in the oral cavity (4).

Regarding the extrinsic source of acids, it was found that it could be due to the excessive intake of acidic items such as carbonated drinks, fruit juices, wines, herbal teas, energy drinks, and supplements such as hydrochloric acid (taken for indigestion), chewable or effervescent vitamin $\mathrm{C}$, aspirin, and some oral hygiene products, including some mouth rinses (5). Oral administration of medication has also been suggested as an extrinsic cause of dental erosion because of the low $\mathrm{pH}$ and high titratable acidity of some medicines used for chronic diseases (6). It was reported that the erosive potential of a substance is not only dependent on $\mathrm{pH}$ value and acid type, but is also strongly influenced by the titratable acidity (the greater the titratable acidity, the longer it takes saliva to neutralize the acid). Medicines usually have low endogenous $\mathrm{pH}$ and high titratable acidity, calcium chelation properties and adhesion to the dental surface. Accordingly, several cases of tooth erosion have been attributed to oral administration of medicines (7).

Acids are added to drug formulations as buffering agents to maintain chemical stability, control tonicity or to guarantee physiological compatibility and to improve flavor, and thereby increase the palatability to children. Citric acid is the primary acid used in the oral medicines, and in spite of being a weak acid, it is a potent erosive agent because of its ability to chelate calcium in hydroxyapatite. This subsequently increases the dissolution rate of hydroxyapatite crystals (8). Furthermore, the risk of dental erosion can be increased when medications are used for treatment of chronic diseases with a high frequency of ingestion (two or more times per day), at bedtime or when they have side effects such as reduction of salivary flow rate (9).

Drugs with antihistamine are prescribed by pediatricians for relieving symptoms of seasonal allergies such as runny nose; sneezing; itchy, watery eyes or itching of the nose and throat. Specifically, Claritine syrup (Schering-Plough) is an antihistamine liquid formulation that is widely prescribed by pediatricians and therefore, consumed by a significant number of children (10). 
Claritine syrup: presents characteristics that may well provide erosive potential as its low endogenous $\mathrm{pH}$, high titrable acidity, presence of citric acid, absence of fluoride and phosphate, and presence of minimal quantity of calcium in its composition (11). Therefore, several studies reported the erosive effect of claritine syrup in dentistry (12-16).

Remineralization of erosive lesions using different remineralizing agents have raised great concerns. Control of mineral loss caused by erosion has been a challenge for researchers; therefore, there are many new remineralizing agents in the dental market which claim a protection or treatment for the situation. In recent years casein phosphopeptide-amorphous calcium phosphate (CPPACP) have also developed a great concern in modern dentistry for having anti-cariogenic as well as anti- erosive properties. This technology was developed by Eric Reynolds and co-workers at the University of Melbourne. It has since been incorporated into tooth paste and advertised as GC Tooth Mousse (17).

Under acidic conditions, CPP-ACP binds readily to the surface of the tooth and the casein derived phophopeptides buffers free calcium and phosphate ions depositing a high concentration of ACP clusters in close proximity to the tooth surface. In a consequence, that will raise calcium and phosphate level in plaque maintaining a state of super saturation, inhibiting demineralization and enhancing remineralization (18). Several studies demonstrated that CCP-ACP increased the microhardness of eroded enamel (1921). Up till now, there is no published research concerning the role of CCP-ACP in reducing dental erosion due to medication. So, in view of the above considerations, the present in vitro study aimed to evaluate the effect of CCPACP on the surface microhardness of eroded primary tooth enamel by antihistamine syrup. It was hypothesized that the treatment of eroded enamel with CCP-ACP would enhance its surface microhardness.

\section{MATERIALS AND METHODS}

Twenty freshly exfoliated sound primary anterior teeth were collected from public hospitals in Alexandria and outpatient clinic of the Faculty of Dentistry, Alexandria University. Teeth were cleaned, and then they were carefully examined with a magnifying lens. Teeth with presence of cracks and developmental defects were excluded from the study.

\section{Materials}

Claritine syrup (Schering-Plough)(22): it is an antihistamine syrup which contains $1 \mathrm{mg} / \mathrm{ml}$ micronized loratadine, citric acid, artificial flavor, glycerin, propylene glycol, sodium benzoate, sugar and water.

CPP-ACP paste (GC Tooth Mousse, GC, Tokyo, Japan) (23): it is water based; sugar free (cream) containing Recaldent ${ }^{\mathrm{TM}}$ which is a trademark used under license and is milk derived with lactose content less than $0.01 \%$. GC mousse is composed of the following ingredients: Water, CPP-ACP, glycerol, D-sorbitol, CMC-Na, propylene glycol, silicon dioxide, titanium dioxide, xylitol, phosphoric acid, flavoring, zinc oxide, sodium saccharin, ethyl p-hydroxybenzoate, magnesium oxide, guar gum, propyl p-hydroxybenzoate, butyl p-hydroxybenzoate

Artificial saliva was used and prepared by mixing 500 $\mathrm{ml}$ distilled water with $1.2 \mathrm{~g}$ potassium chloride, $0.843 \mathrm{~g}$ sodium chloride, $0.051 \mathrm{~g}$ magnesium chloride, $20 \mathrm{ml}$ stock solution of tri-calcium phosphate $1 \%$ (10.5 g TCP and $200 \mathrm{ml}$ of $1.0 \mathrm{M}$ hydrochloric acid) and Carboxy- methylcellulose. Sodium hydroxide $(0.05 \mathrm{M})$ was added to the mixture to have a $\mathrm{pH}$ 6.8. (24)

\section{Equipment}

Vickers microhardness testing machine (Model LM-100, FM 1159 Leco Corpration Michnigin,USA)

Diamond saw (Isomet 4000 microsaw, Buehler,USA) was used to cut each primary anterior tooth into two equal halves.

Ph meter (MP 230 PH Meter, METTLER TOLEDO) was used to measure the value of $\mathrm{Ph}$ of the antihistaminic syrup.

\section{Grouping}

All the selected 20 teeth were sectioned buccolingually into 2 equal halves and were devided into 2 groups:

Group I (Study Group): consisted of 20 teeth specimens and were subjected to erosion with antihistaminic agent then treated with CPP-ACP (GC Tooth Mousse ${ }^{\circledR}, \mathrm{GC}$, Japan).

Group II (Control Group): consisted of 20 tooth specimens and subjected to erosion wih the antihistaminic syrup and were left untreated.

The $\mathrm{pH}$ of the antihistaminic syrup was measured, before its use as a demineralizing agent by a ph electrode meter (MP 230 PH Meter, METTLER TOLEDO). It was performed at the central lab of the Faculty of Pharmacy. The PH of the syrup was found to be 3.261

\section{Preparation of the specimens (2)}

The teeth were thoroughly cleaned using fluoride free pumice and were stored in saline solution until required for use. The roots were removed at the cement-enamel junction with a water-cooled diamond saw of a precision sectioning machine (Isomet 4000 microsaw,Buehler,USA).Teeth were sectioned along their buccolingual axis into two equal halves; one half served as a study, and the other half as control. Each tooth fragment was invested in a Teflon mold, embedded in a flowable composite polymerized with their labial surface facing upwards. The labial surface of the specimens was grinded using silicon carbide papers (grades600-1200) under water irrigation and polished to produce a flat surface using a water-cooled low-speed polishing machine. After the polishing procedure, samples were viewed under an optical microscope in order to confirm that the surfaces were flat, polished, and free of irregularities that might interfere with hardness testing.

\section{Experimental protocol}

Group I (study group)

Specimens of the study group were labelled from 1 to 20 and were assessed for surface microhardness (initial assessment) (baseline assessment) before any erosive challenge.

Formation of erosive lesion (13): The specimens were immersed in Claritine syrup for 30 min every 12 hours for 12 days in a red capped container. Between the erosion cycles; the specimens were rinsed in distilled water for 5 seconds and stored in artificial saliva in a red capped container till the time of next immersion cycle. The artificial saliva was refreshed daily and the Claritine syrup was replaced before each cycle (8).

Remineralization (21-25): GC tooth mousse was applied using a cotton tip and was left in contact with the tooth surface for three minutes, according to the manufacturer's instruction. The specimens were rinsed with distilled water for 5 seconds and then were stored in the artificial saliva. The tooth mousse application was applied once daily 
(every 24 hours) for 10 consecutive days. After 10 days the 20 specimens were assessed for surface microhardness (second assessment) (remineralization assessment).

\section{Group II (control group)}

Specimens of the control group were labeled from $1^{-}$to $20^{-}$ and were assessed for surface microhardness (initial assessment) (baseline assessment) before any erosive challenge.

Formation of erosive lesion: The specimens were immersed in Claritine syrup for 30 min daily every 12 hours for 12 days in a blue capped container. Between the erosion cycles; the specimens were rinsed in distilled water for 5 seconds and stored in artificial saliva in a blue capped container till the time of next cycle. The specimens were left untreated. After 12 days of erosion they were assessed for surface microhardness (final assessment).

\section{Surface microhardness assessment (26)}

Microhardness testing was done-using a microhardness tester (Model LM-100, FM 1159 Leco Corpration Michnigin, USA)-as a base line evaluation and after the 12 days of erosion for the control group specimens. Regarding the study group specimens, microhardness testing was done as a base line evaluation, after treatment with GC tooth mousse. The surface Micro-hardness (SMH) of the specimens was determined using Digital Display Vickers Micro-hardness Tester with a Vickers diamond indenter and a 20X objective lens. A load of $50 \mathrm{~g}$ was applied to the surface of the specimens for 15 seconds.

Table (1): Mean (SD) difference of the surface microhardness at baseline and after erosion with the antihistaminic drug.

\begin{tabular}{|c|c|c||}
\hline & Baseline & After erosion \\
\hline Min - max & $142.00-208.50$ & $75.50-159.30$ \\
\hline Mean (SD) & $180.88(19.70)$ & $96.48(19.66)$ \\
\hline Mean (SD) difference & $84.40(20.19)$ \\
\hline $\begin{array}{c}\text { Paired t test } \\
\text { P value }\end{array}$ & $\begin{array}{c}18.70 \\
<0.0001^{*}\end{array}$ \\
\hline
\end{tabular}

*: Statistically significant at $\mathrm{P} \leq 0.05$.

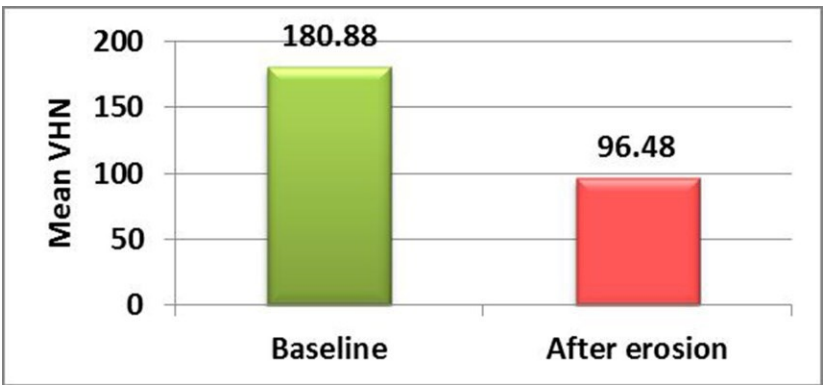

Figure 1: Showing the mean (SD) surface microhardness at baseline and after erosion by the antihistamine syrup.

Five indentations were equally placed over a circle of 1$\mathrm{mm}$ diameter at the middle third of the specimens. The diagonal length of the indentations was measured by built in scaled microscope and Vickers values were converted into micro-hardness values. SMH was obtained using the following equation:
$\mathrm{HV}=1.854 \mathrm{P} / \mathrm{d} 2$ where, $\mathrm{HV}$ is Vickers hardness in $\mathrm{Kef} / \mathrm{mm} 2, \mathrm{P}$ is the load in Kef and $\mathrm{d}$ is the length of the diagonals in $\mathrm{mm}$.

\section{Statistical analysis}

Descriptive statistics were calculated as minimum, maximum, mean and standard deviation of Vickers hardness number. Differences in values between before and after interventions were compared using paired t test. Significance level was set at 5\%. Statistical analysis was done using SPSS version 17.0. Bar charts were used for graphical presentation.

\section{RESULTS}

After erosion with the antihistamine syrup, there was a statistically significant decrease in surface microhardness with a mean difference $84.40( \pm 20.19)$ and $\mathrm{P}$ value was $<$ 0.0001. (Table (1) and fig. 1). While after treatment with CPP-ACP paste, there was a statistically significant increase in surface microhardness with a mean difference $11.56( \pm 19.19)$ and $P$ value was 0.01. Table (2) and fig. 2

Table (2): Mean (SD) difference of the surface microhardness after treatment with GC tooth mousse following erosion by the antihistaminic drug.

\begin{tabular}{|c|c|c|}
\hline & $\begin{array}{c}\text { After erosion } \\
\text { (control group) }\end{array}$ & $\begin{array}{c}\text { After treatment } \\
\text { (study group) }\end{array}$ \\
\hline Min - max & $75.50-159.30$ & $77.90-187.70$ \\
\hline Mean (SD) & $96.48(19.66)$ & $108.04(29.06)$ \\
\hline $\begin{array}{c}\text { Mean (SD) } \\
\text { difference }\end{array}$ & $11.56(19.19)$ \\
\hline $\begin{array}{c}\text { Paired t test } \\
\text { P value }\end{array}$ & 2.69 \\
\hline
\end{tabular}

*: Statistically significant at $\mathrm{P} \leq 0.05$.

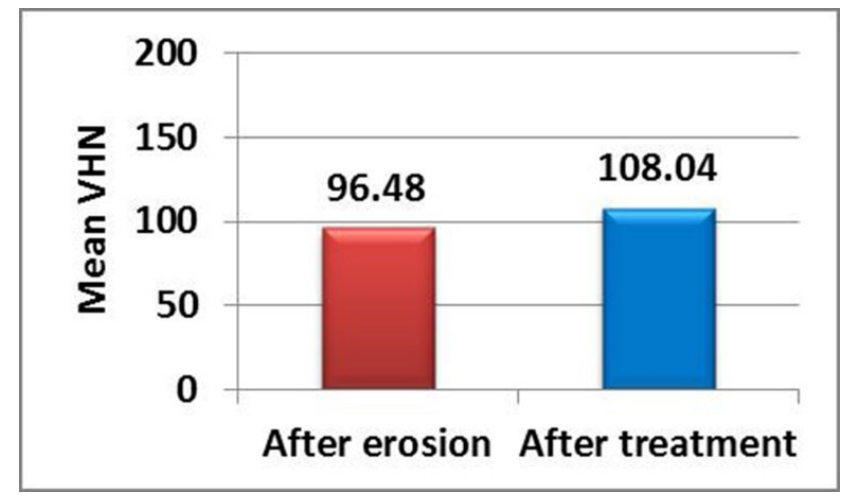

Figure 2: Showing the mean (SD) difference of the surface microhardness after treatment with GC tooth mousse following erosion by the antihistaminic drug.

\section{DISCUSSION}

Dental erosion occurring in early childhood may compromise the dentition for the child's entire lifetime and this will definitely impact their life quality and necessitate costly dental treatments in adult life. As well, there is a growing concern about dental erosion as it often develops silently until it causes a severe signs and symptoms (27). 
Many in vitro studies have already reported that oral liquid medicines could be correlated to dental erosion (12, 28, 29).

Most of the children are incapable of swallowing medications in the tablet form. Therefore, other formulations, such as liquid medications have been employed to solve this issue (30). Unfortunately, these liquid medications were shown to be predominantly harmful when consumed by children on a regular course of chronic condition therapy (6). Also, It should also be expected that those children may be exposed to other erosive sources, such as the intake of acidic diet and / or having a gastric disorder. This will intensify the acid challenges carried out on the tooth structure (14).

The medicine selected for this research (claritine) presented characteristics that may increase its erosive potential such as low endogenous $\mathrm{Ph}$, high titratable acidity, presence of citric acid, lack of fluoride and phosphate, and negligible amount of calcium in its composition (12). That was in agreement with the measured value of the drug ph in the present study and which was found to be of an acidic value (3. 261). Also, claritine syrup is widely handled in public pediatric hospitals and healthcare services and therefore, consumed by a significant number of children (10). Costa et al (12), Valinoti et al (13), Xavier et al (14) and Alexandria et al (16) evaluated the erosive effect of Claritine, alone or with other medications on different tooth substrates.

Erosion studies have been generally performed in vitro conditions, not only because several parameters can be standardized extraorally but also due to lack of sensitivity in vivo conditions. On the other hand, it is difficult to mimic the oral environment exactly (31).

It has been observed that primary and permanent teeth differ from each other in structure and morphology. Dental erosion can progress faster in primary teeth than in permanent teeth as the former are known to be less mineralized and not as mature as the latter. However; most of the studies were performed on a permanent tooth substrate. In our study, deciduous teeth were used (32).

It is well known that saliva is considered as an important protective factor against dental erosion. This is based on the fact that saliva is responsible for the formation of tooth pellicle (salivary proteins based pellicle). This pellicle is found to be a diffusion barrier which inhibits direct contact between acids and the tooth surface, thus preventing the demineralization process. Also, healthy saliva contains a variety of carbonate salts which could help in acids neutralization (33). For this reason, in the current study, artificially prepared saliva was the chosen media to be used between erosive immersion cycles due to its reported ability to exert similar remineralizing effect as that of fresh human saliva.

Softening of enamel surface due to dental erosion is best evaluated by measuring its microhardness. This method can quantify the amount of occurred damage caused by erosive substances (8). So the quantitative evaluation in the current study was done by measuring the surface microhardness. This method was used in many studies such as Tantbirojn et al (34) who reported that treatment with CPP-ACP paste significantly increased the surface microhardness of bovine enamel softened by a cola drink.

Regarding the erosive challenge by medication, most of studies preferred the immediate assessment of dental erosion after a single exposure to the medication such as the study done by Xavier et al (14), but in other studies, multiple exposures were performed such as the exposure over 12 days by Valinoti et al (13), 14 days by Costa CC et al (12) and 28 days by Scatena $\mathrm{C}$ et al (8). The advantage of using a sequence of repeated exposures is that it leads to obtain reliable results, because changes can be noticed after several challenges, even if not recognized after a single exposure (35). For this reason, multiple exposures were preferred to be adopted in the current study.

The erosive challenge of the enamel specimens was to immerse the samples of both control and study groups in Claritine syrup for 30 min every 12 hours for 12 days. This regimen was selected to simulate the long term use of antihistamine syrup and it was similar to the erosive challenge done by valenoti et al (13).

The results of microhardness revealed that twelve daily acid challenges with claritine syrup were able to cause extensive enamel demineralization and interns, a marked decrease in the surface microhardness of the teeth specimens was found. These findings were in accordance with those of Valinoti et al (13) and Costa et al (12).

The need for the development of a nontoxic remineralizing agent, that could supplement the effects of fluoride, has been highlighted in recent years (36). Casein phosphopeptideamorphous calcium phosphate has the privilege to be used by children because it appears to be very safe for use in oral care products, dental professional products, and foodstuffs. The alkaline, stable, and highly soluble CPP-ACP has been trademarked as Recaldent and has now been incorporated into sugar-free gum and mints and in dental professional products such as Tooth Mousse. Another advantage of CPP-ACP is that it can be used safely by people with lactose intolerance. However, Products containing CPP-ACP should not be consumed by people with milk protein allergies (37). In the present study, CCP-ACP was selected to evaluate its effect as an antierosive material

GC Tooth Mousse is a water-based, lactose-free crème containing 10\% w/w Recaldent CPP-ACP. When CPPACP is applied in the oral environment, it will bind to biofilms, plaque, bacteria, hydroxyapatite, and soft tissue, localizing bioavailable calcium and phosphate (2). It has been proposed that the remineralizing capacity of CPPACP owes to its ability to localize ACP at the tooth surface; thereby it helps to maintain a state of supersaturation with respect to the enamel which depresses demineralization and promotes remineralization (18). Additionally, the added flavoring agent helps to stimulate salivary flow to enhance its effectiveness (38).

In the present study, CPP- ACP (TM) was applied as a topical coating on the eroded specimens of study group once daily for 10 consecutive days. . This was similar to the application of CCP-ACPF and CCP-ACP adopted by Darshan et al (21) and Talaat et al (25) respectively. These two regimens showed significant remineralization, in vitro.

Results of hardness testing revealed that treatment with CCP-ACP paste significantly increased the mean surface microhardness of the eroded study group specimens, indicating remineralization. The current results are supported by those of Panish et al (19), Vongsawan et al (20) who proved that CCP-ACP was effective in increasing the hardness and enhancing the remineralization of eroded enamel in vitro, respectively. Likewise, concerning the remineralizing effect of $\mathrm{CCP}-\mathrm{ACP}$, results 
of hardness testing were in agreement with Tantbirojn et al (34) who conducted an in vitro study, in which colasoftened enamel surfaces were treated with CCP-ACP. It was found that $\mathrm{CCP}-\mathrm{ACP}$ rehardened the surfaces significantly as compared with fluoride-treated surfaces.

On the other hand, there was a disagreement with the results of Wiegand A et al (40) who claimed that CCPACP was not effective in reducing enamel loss significantly when compared to the effect of fluoridated tooth paste or fluoride mouthrinse.

The lack of reported studies that tested the same methodology and materials did not allow for a reliable comparison with published outcomes.

\section{CONCLUSIONS}

Under the conditions of this in vitro study; it was concluded that:

1. Antihistamine syrup was able to induce a severe erosive effect on primary teeth enamel. So, knowledge of the erosive potential of these commonly used syrups is mandatory. As to clinicians and especially pediatric health professionals.

2. Casein phosphopeptide- amorphous calcium phosphate paste was an effective treatment against dental erosion induced by antihistamine syrup.

\section{ACKNOWLEDGEMENT}

I would like to thank Prof. Maha Tantawy and Dr. Nancy Mamdouh for their continuous support and valuable advices during conduction of this study

\section{CONFLICT OF INTEREST}

The authors declare that they have no conflict of interest.

\section{REFERENCES}

1. Harley K. Tooth wear in the child and the youth. $\mathrm{Br}$ Dent J. 1999; 186: 492-6.

2. Poggio C, Lombardini M, Dagna A, Chiesa M, Bianchi S. Protective effect on enamel demineralization of a CPPACP paste: an AFM in vitro study. J Dent. 2009; 37:94954.

3. Wiegand A, Attin T. Occupational dental erosion from exposure to acids: a review. Occup Med (Lond). 2007; 57:169-76.

4. Ren YF. Dental Erosion: Etiology, Diagnosis and Prevention, a Peer Review Publication, 2013. Pages 87-95.

5. Taji S, Seow WK. A literature review of dental erosion in children. Aust Dent J. 2010; 55: 358-67.

6. Babu KL, Rai K, Hedge AM. Pediatric liquid medicaments-do they erode the teeth surface? An in vitro study: part I. J Clin Pediatr Dent. 2008; 32: 189 94.

7. Moss SJ. Dental erosion. Int Dent J. 1998; 48:529-39.

8. Scatena C, Galafassi D, Gomes-Silva JM, Borsatto $\mathrm{MC}$, Serra MC. In vitro erosive effect of pediatric medicines on deciduous tooth enamel. Braz Dent J. 2014; 25: 22-7.

9. Van Rijkom HM, Truin GJ, Frencken JE, König KG, van 't Hof MA, Bronkhorst EM, et al. Prevalence, distribution and background variables of smoothbordered tooth wear in teenagers in The Hague, the Netherlands. Caries Res. 2002; 36: 147-54.
10. Del Cuvillo A, Sastre J, Montoro J, Jáuregui I, Ferrer M, Dávila I, et al. Use of antihistamines in pediatrics. J Investig Allergol Clin Immunol. 2007; 17: 28-40.

11. Viviane P, Lucianne M, Thiago IV, Monique C, Michele V, Lucio MC. Effect of Dilution on the PH and Titratable Acidity of Pediatric Syrup Medicines.J bacterial parasitol. 2013; 2: 595-62.

12. Costa CC, Almeida IC, Costa Filho LC. Erosive effect of an antihistamine-containing syrup on primary enamel and its reduction by fluoride dentifrice. Int J Paediatr Dent. 2006; 16: 174-80.

13. Valinoti AC, Pierro VS, Da Silva EM, Maia LC. In vitro alterations in dental enamel exposed to acidic medicines. Int J Paediatr Dent. 2011; 21: 141-50.

14. Xavier AF, Moura EF, Azevedo WF, Vieira FF, Abreu MH, Cavalcanti AL. Erosive and cariogenicity potential of pediatric drugs: study of physicochemical parameters. BMC Oral Health. 2013; 10: 13-71.

15. Xavier AF, Abreu MHNG, Melo JBCA, Anselmo GCS, Cavalcanti AL. Changes in microhardness and morphology of the adamantine structure as a function of the exposure time to different drugs. Braz Res Pediatr Dent Integrated Clinic. 2015; 15: 279-89.

16. Alexandria AK, Meckelburg NA, Puetter UT, Salles JT, Souza IP, Maia LC. Do pediatric medicines induce topographic changes in dental enamel? Braz Oral Res. 2016; 30:159-87.

17. Reynolds EC, Cai F, Cochrane NJ, Shen P, Walker GD, Morgan MV, et al. Fluoride and casein phophopeptide- amorphous calcium phosphate. J Dent Res. 2008; 87: 344-8.

18. Reema SD, Lahiri PK, Roy SS. Review of casein phosphopeptides- amorphous calcium phosphate. Chin J Dent Res. 2014; 17: 7-14.

19. Panich M, Poolthong S. The effect of casein phosphopeptide- amorphous calcium phosphate and a cola soft drink on in vitro enamel hardness. J Am Dent Assoc. 2009; 140; 455-60.

20. Vongsawan K, Surarit R, Rirattanapong P. The effect of high calcium milk and casein phosphopeptideamorphous calcium phosphate on enamel erosion caused by cholinated water. Southeast Asian J Trop Med Public Health. 2010; 41:1494-9.

21. Darshan HE, Shashikiran ND. The effect of McInnes solution on enamel and the effect of Tooth mousse on bleached enamel. J Conserv Dent. 2008; 11:86-91.

22. Claritin Information. 2016. Available at: http://www.rxlist.com/claritin-drug.htm

23. Cem G, Ebru C, Seval Ö. Remineralizing effect of different topical agents on occlusal surfaces with or without caries: an in vitro evaluation study using electrical resistance measurements. Clin Dent and Res. 2012; 36: 4-9.

24. Kawai K, Heaven TJ, Retief DH. In vitro dentine fluoride uptake from three fluoride-containing composites and their acid resistance. J Dent. 1997; 25: 291-6.

25. Talaat DM, Mahmoud A. Acid Resistance of Enamel Subsurface Lesions Treated with Casein Phosphopeptide Amorphous Calcium Phosphate Fluoride. J Dent Child. 2015; 82: 70-5.

26. Badr SB, Ibrahim MA. Protective effect of three different fluoride pretreatments on artificially induced dental erosion in primary and permanent teeth. Am J Sci. 2010; 6:424-51. 
27. Viviane P, Beatriz F, Michele V, Lúcio MC, Eduardo $\mathrm{S}$, Lucianne M. Erosive effect of an antihistamine liquid formulation on bovine teeth: influence of exposure time. Braz J Oral Sci. 2010; 9: 20-4.

28. Cavalcanti AL, De Sousa RI, Clementino MA, Vieira FF, Cavalcanti CL, Xavier AF. In vitro analysis of the cariogenic and erosive potential of paediatric antitussive liquid oral medications. Tanzan J Health Res. 2012; 14: 139-45.

29. Tupalli AR, Satish B, Shetty BR, Battu S, Kumar JP, Nagaraju B. Evaluation of the erosive potential of various pediatric liquid medicaments: An in-vitro Study. J Int Oral Health. 2014; 6: 59-65.

30. Arora R, Mukherjee U, Arora V. Erosive potential of sugar free and sugar containing pediatric medicines given regularly and long term to children. Indian J Pediatr. 2012 79: 759-63.

31. West NX, Hughes JA, Addy M. Erosion of dentine and enamel in vitro by dietary acids: the effect of temperature, acid character, concentration and exposure time. J Oral Rehabil. 2000; 27: 875-80.

32. Hunter ML, West NX, Hughes JA, Newcombe RG, Addy M. Relative susceptibility of deciduous and permanent dental hard tissues to erosion by a low $\mathrm{pH}$ fruit drink in vitro. J Dent. 2000; 28: 265-70.

33. Hara AT, Ando M, González-Cabezas C, Cury JA, Serra MC, Zero DT. Protective effect of the dental pellicle against erosive challenges in situ. J Dent Res. 2006; 85: 612-6.

34. Tantbirojn D, Huang A, Ericson MD, Poolthong S. Change in surface hardness of enamel by a cola drink and a CPP-ACP paste. J Dent. 2008; 36:74-79.

35. Barbour ME, Lussi A, Shellis RP. Screening and prediction of erosive potential. Caries Res. 2011; 45: 24-32.

36. Bhagavatula P, Levy SM, Broffitt B, WeberGasparoni K, Warren JJ. Timing of fluoride intake and dental fluorosis on late-erupting permanent teeth. Community Dent Oral Epidemiol. 2016; 44: 32-45.

37. Al-Batayneh OB. The clinical applications of Tooth Mousse TM and CPP-ACP products in caries prevention: evidence- based recommendations. Pediatr Dent J. 2009; 4: 8-12.

38. Somasundaram P, Vimala N, Mandke LG. Protective potential of casein phosphopeptide amorphous calcium phosphate containing paste on enamel surfaces. J Conserv Dent. 2013; 16: 152-6.

39. Wiegand A, Attin T. Randomized in situ trial on the effect of milk and CPP-ACP on dental erosion. J Dent. 2014; 42: 1210-5. 